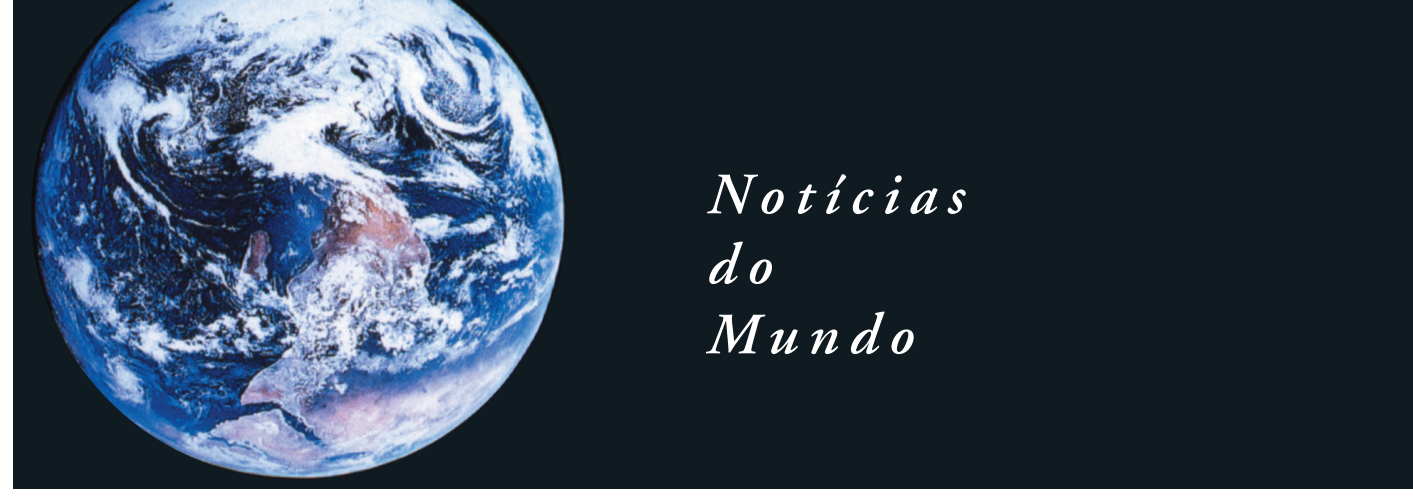

VACINA PREVENTIVA Com os avanços em prevenção ainda insuficientes, houve aproximadamente 2,6 milhões de novos casos de infecção pelo HIV em 2009, segundo relatório do UnAids. Um estudo epidemiológico do Instituto de Pesquisa Clínica Evandro Chagas (Ipec/Fiocruz) mostrou que, somente no Brasil, o impacto de uma vacina preventiva já seria notável. Se fosse iniciada no país em 2015, a imunização poderia reduzir em $73 \%$ as novas infecções e em $30 \%$ o número de mortes relacionadas à Aids até 2050 , quando $80 \%$ da população adulta brasileira estaria imunizada por uma vacina com $40 \%$ de eficácia.

0 efeito estimado pelos pesquisadores, porém, dificilmente poderia ser medido nos mesmos moldes em escala global devido ao nível de detalhamento necessário. "São informações difíceis de ser homogeneizadas e mesmo obtidas globalmente", explica a pesquisadora Maria Goretti Fonseca, do Ipec. 0 instituto realizou o trabalho em parceria com o Futures Institute, dos Estados Unidos, e a International Aids Vaccine Initiative (lavi). "O Futures Institute e a lavi vêm trabalhando em outros países, mas sempre individualmente, porque as epidemias são diferentes", explica Fonseca.

Cassius Guimarães

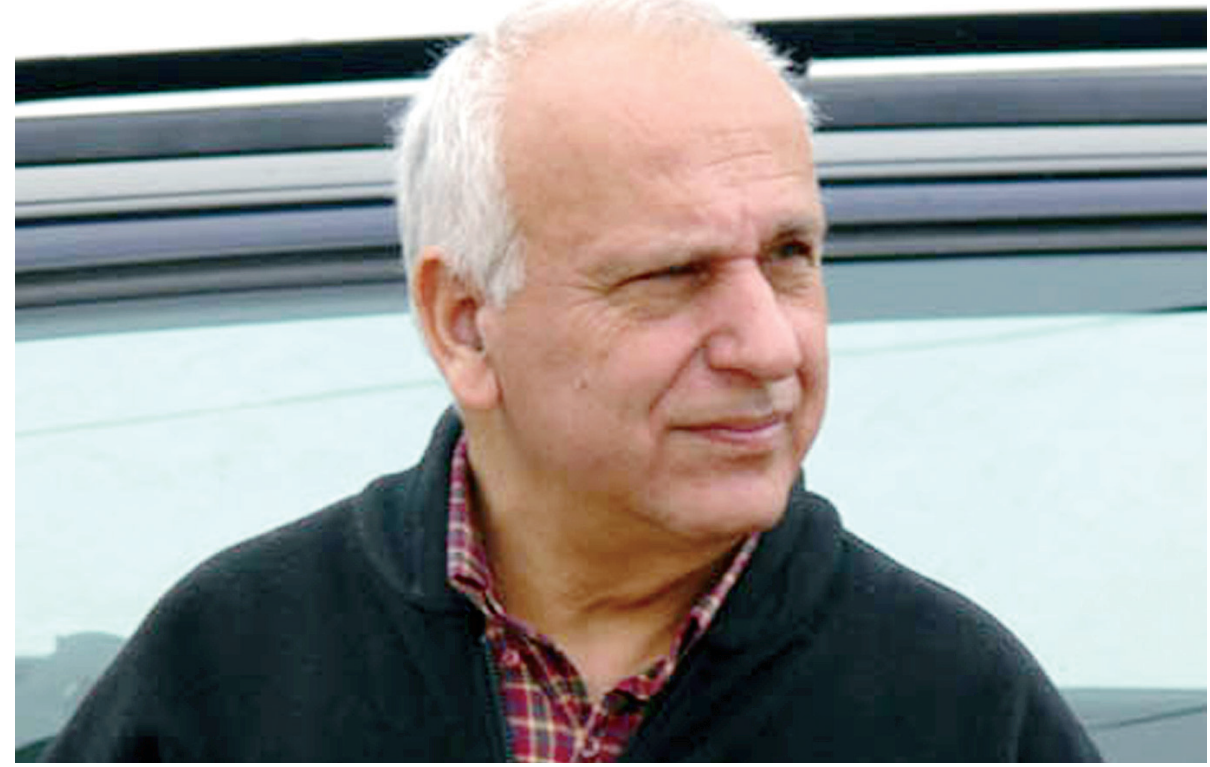

José Croca contribuições para a quebra de paradigmas na física quântica

ENTREVISTA

\section{Uma nova teoria causal e não linear para explicar fenômenos da mecânica quântica}

Pode-se dizer que o físico português José Croca está no olho do furacão de um complexo e instigante debate da mecânica quântica (ou teoria quântica), a menina dos olhos da física moderna. Orientado por Andrade e Silva, que, por sua vez, foi auxiliar de Louis Broglie (1892-1987), prêmio Nobel de Física de 1929, seus recentes estudos sobre onduletas contribuíram para a revisão de paradigmas importantes da física quântica e lhe renderam dois prêmios, um internacional - a medalha do SantilliGalilleu (2008) - e outro nacional, o prêmio da Federação Internacional Racionalista. Pode-se dizer que Croca estava no lugar certo, na hora certa e com um estudo pertinente em mãos. Nesta entrevista, Croca, que é coordenador do grupo de pesquisa em Fundamentos Filosóficos da Física Quântica, do Centro de Filosofia das Ciências da Universidade de Lisboa, fala sobre a proposta de se estudar a validade das teorias da Escola de Copenhague o que já produz resultados interessantes. Autor do livro Towards a nonlinear quantum physics (World Scientific, 2003) ele afirma que "pelo 
Para começar, gosto de dizer que a palavra interpretação, comumente utilizada, talvez não seja a mais adequada para descrever o que realmente se passa. Na verdade, aquilo que a nossa Escola de Lisboa propõe não é uma nova interpretação do formalismo quântico mas, antes, uma nova teoria causal e não-linear que, naturalmente, contém, do ponto de vista formal, na sua aproximação linear, a mecânica quântica tradicional. Sabemos que Niels Bohr apresentou, pela primeira vez, no famoso Congresso Internacional da Física, em Como, Itália, no início de setembro de 1927, a sua derivação das relações de Heisenberg como a expressão matemática do seu princípio da complementaridade. Esta derivação matemática resulta diretamente das propriedades da análise não-local e não-temporal de Fourier, promovida por esse grande físico ao estatuto de uma verdadeira ontologia. Ora, a expressão por mim desenvolvida resulta, do ponto de vista matemático, da substituição da análise de Jean-Baptiste J. Fourier pela análise local por onduletas, de Jean Morlet [veja box]. Dois anos mais tarde, após a minha estadia na Universidade de Rochester (EUA), mostrei, perante os maiores especialistas mundiais no assunto, que existem situações experimentais concretas, muito especiais, que no seu dia a dia falsificam a validade geral das relaçôes de Heisenberg. Ou seja, existe todo um domínio experimental em expansão, que está para além das possibilidades de descrição das relações de Heisenberg e que, até então, eram pretensamente consideradas como a última e derradeira palavra. Com efeito, trata-se das observações realizadas com os chamados super microscópios desenvolvidos recentemente. Convém não esquecer que a fundamentação conceitual da mecânica quântica tradicional, ou bohreana, se apoia no princípio da complementaridade, que, por sua vez, tem como expressão matemática as relaçóes de Heisenberg. Assim, mostrar experimentalmente que existem fenômenos no domínio da microfísica não explicados por essas relaçóes tomadas como inquestionáveis e absolutas é o mesmo que mostrar que a mecânica quântica ortodoxa não é uma teoria completa e, portanto, chegou a altura de ser substituída por uma teoria mais geral.

Desde que a física quântica foi desenvolvida, a partir dos anos 1920 , suas previsões têm sido comprovadas experimentalmente com precisão. Porém, não se chegou ainda a um consenso teórico sobre o modo como esses fenômenos ocorrem. Como isso é possível?

Mais uma vez, gosto de dizer que a mecânica quântica ortodoxa ou bohreana é uma grande teoria. Provavelmente uma das maiores teorias que o ser humano produziu até hoje. No entanto, devemos sempre ter presen- te que se trata, em última instância, de uma criação humana e, por isso, necessariamente limitada. De igual modo a teoria de Newton, a mecânica clássica, também é seguramente uma grande teoria. No entanto, no início do século passado, mostrou-se que tinha limites de validade e, portanto, não era, como se afirmava, a teoria completa e infalível válida para todas as escalas de observação e descrição. Nessas condições, pretender que a mecânica quântica ortodoxa seja uma teoria completa e definitiva, em suma, a última verdade, constitui, a meu ver, um ato mais religioso que científico, ou então, na melhor das hipóteses, uma atitude ingênua. Como sabemos, a mecânica quântica surgiu para explicar o problema do dualismo onda-partícula. Esse problema resulta do fato observado que os entes quânticos têm um comportamento aparentemente bizarro, ora se comportam como ondas, ora como partículas. Trata-se de um fenômeno tipicamente não-linear e que, portanto, para a sua adequada descrição tornava-se necessário abandonar o paradigma habitual linear cartesiano. Niels Bohr, em vez de enfrentar essa situação, vai tentar descrever essa não-linearidade inerente aos fenômenos da escala quântica com auxílio do seu princípio da complementaridade, arrastando então ao postulado da redução ou colapso da função de onda. Desse modo, Bohr 


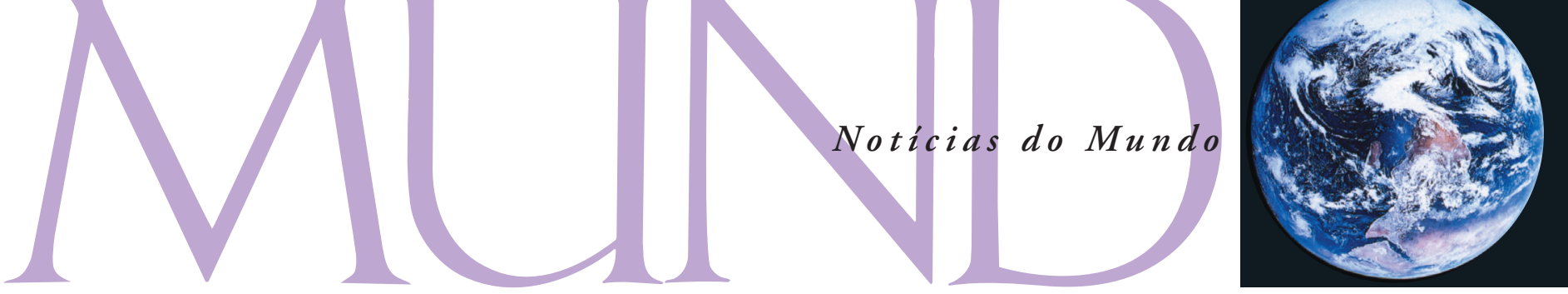

constrói então uma teoria pretensamente linear, quer dizer, linear em todo o domínio, exceto no da medida [física], [onde se dá] o colapso da função da onda. Dessa inconsistência básica, dessa recusa em aceitar o não-linear como ponto de partida resultaram todos os paradoxos e problemas com que se tem enfrentado a mecânica quântica ortodoxa. Agora, que estamos mais distanciados no tempo, e, portanto, temos uma visão mais clara do que foi a física do século XX, temos consciência de que é necessário desenvolver toda uma nova física para explicar fenômenos essencialmente não-lineares. Essa física partirá, naturalmente, do pressuposto de que os fenômenos que se pretende descrever à escala quântica necessitam de uma abordagem nãolinear. Com base nessa nova onto- logia, foi possível elaborar, nos seus fundamentos, uma física quântica mais geral onde a não linearidade intrínseca dos fenômenos à escala quântica é assumida desde o início.

\section{Recentemente, o senhor publicou o} livro Diálogos sobre física quântica (Capax Dei. 2010), em conjunto com Rui Moreira, voltado para leigos. 0 senhor acredita que a percepção pública sobre a física é equivocada?

Quando consultamos os livros correntes de divulgação científica, verificamos que arande maioria dos autores não é especializada no assunto que trata. Fato tanto mais verdadeiro quando se trata de física quântica. Por outro lado, também se verifica que muitos desses livros procuram, sobretudo, o sensacionalismo. Assim, quanto mais confusão, quanto

\section{ANÁLISE DE Fourier E ANÁlISE DAS ONDULETAS}

A análise de Fourier é uma técnica matemática usada para descrever ondas harmônicas. Ao ser usada para explicar o comportamento das partículas elementares, ela trouxe como resultado a ideia de que as ondas são infinitas no espaço e no tempo, sendo, portanto, impossível determinar sua origem ou prever o seu fim. Mas, as ondas físicas reais são finitas, mesmo as micro partículas. Assim, nos anos 1980, surgiu uma nova ferramenta matemática para explicar os fenômenos das ondas e que poderiam ser aplicadas às particulas elementares na física quântica. O geofísico Jean Morlet, empenhado em prever com maior eficácia a localização de jazigos de petróleo, desenvolveu um processo chamado mais tarde de análise local em onduletas ou ondas finitas. Esta análise permite aceitar como natural que um impulso finito, uma onda física real, pode ter, na verdade, uma frequência e, portanto, uma energia bem definida.

mais misteriosa e esotérica uma teoria for, parecerá melhor discorrer sobre ela. Apesar de, pela sua própria natureza, a mecânica quântica ortodoxa, ser baseada, formal e conceitualmente, na ontologia de Fourier, sendo, portanto, não causal, a grande maioria dos autores que escreve sobre esse tema procura, a todo o custo, descrever os fenômenos quânticos num quadro conceitual [causal e local]. Na realidade, acreditam que é, afinal de contas, um quadro causal e local”. Daqui derivam os chamados paradoxos, as açôes misteriosas, retroações no passado e todo um corolário de fenômenos ditos incompreensíveis que constituem o chamado mistério quântico. Desse modo, ao invés dos leitores desses livros de divulgação científica ficarem mais esclarecidos sobre os reais problemas da física quântica, ficam ainda mais confusos e perplexos.

Foi para colmatar essa lacuna que escrevemos os Diálogos, pois ele procura apresentar de uma forma acessível os problemas relacionados com os fundamentos da física quântica. Nele são apresentados os problemas mais pertinentes, sobretudo, na perspectiva de levar o leitor a poder pensar por si próprio. Desse modo, devidamente informado, o leitor avisado poderá ter uma opiniāo pessoal fundamentada sobre esse estranho e, ao mesmo tempo, fascinante mundo da física quântica. 